\title{
Improved concentration of citrus essential oil by solvent extraction with acetate ionic liquids
}

\author{
Sara Lago, Héctor Rodríguez, Alberto Arce, Ana Soto* \\ Department of Chemical Engineering, University of Santiago de Compostela, E-15782, \\ Santiago de Compostela, Spain
}

\begin{abstract}
Citrus essential oils have numerous applications in multiple sectors, including food, drink and personal care industries. Although mainly constituted by terpenes, the appealing characteristics of citrus essential oils are due to oxyterpenes and other derived oxygenated compounds. In fact, the presence of terpenes in the essential oil may lead to instability or loss of quality. Therefore, concentration of the oil in its oxyterpene compounds by removal of terpenes is desirable. The techniques currently in use for deterpenation of essential oils present a series of issues. In the search for better deterpenation processes, here the use of ionic liquids as solvents in liquid-liquid extraction is explored. In particular, the ionic liquids 1-ethyl-3-methylimidazolium acetate and 1-butyl-3-methylimidazolium acetate are investigated for their extraction of oxyterpene from a modelled citrus essential oil composed of limonene (terpene) and linalool (oxyterpene). The choice of the ionic liquids, in addition to other complementary characteristics, was based on a rationale of potential interactions that can be created preferentially with the linalool. The results show a great performance of these acetate-based ionic liquids, as compared to any other ionic or molecular solvent tested to date, for the concentration in oxyterpenes of the citrus essential oil.
\end{abstract}

KEYWORDS: liquid-liquid equilibrium, 1-ethyl-3-methylimidazolium acetate, 1-butyl-3methylimidazolium acetate, limonene, linalool.

\section{Introduction}

An essential oil is, in principle, the volatile fraction of the components of a plant or its parts, obtained by a physical separation process; although, depending on the nature of such process, the essential oil may also include certain non-volatile residues. At an industrial

\footnotetext{
* Corresponding author. Phone: +34 881816760. E-mail: ana.soto@usc.es
} 
level, citrus essential oils are obtained from the corresponding fruits as co-products in the production of fruit juices. Typical processes for obtaining the essential oil include different versions of cold pressing, as well as distillation techniques (although the latter lead to oils of markedly lower quality), followed by downstream purification stages based on centrifugation or distillation [1]. Essential oils are the main responsible element for the characteristic aromas and flavours of plants.

Citrus essential oils find application in numerous areas. As aromatisers and/or flavouring agents, they are utilised in food and drink industries; in perfumery, cosmetics, soaps, and other cleaning and personal hygiene products; and to mask unpleasant flavours (e.g. certain medicines) and odours (e.g. in the textile, plastics, or paint industries). As a result of multiple biological activities, they can also be used in pharmaceutical and parapharmaceutical products, as well as in aromatherapy [2].

The dozens of components typically present in an essential oil can be categorised into terpenes, their oxygenated derivatives (oxyterpenes), and low molecular weight organic substances (aliphatic alkanes, alcohols, aldehydes, ketones, esters, acids), with non-volatile compounds (paraffins, waxes, etc.) being also present sometimes [3]. In essential oils of citrus fruit peels, the organoleptic characteristics are mainly due to the small proportion of oxygenated terpene derivatives and some other oxygenated compounds (alcohols, aldehydes, ketones, and esters) [4]. Although terpene hydrocarbons constitute over $95 \%$ of these essential oils, they contribute little to the aroma and flavour [1]. In fact, the presence of the terpenes may give rise to problems associated with their insolubility in aqueous or alcohol solutions, or with their proneness to undergo oxidation (with subsequent evolution to resins); both of which result in the deterioration of the oil properties. The direct, non-deterpened oil may be preferable for some purposes, but in general the removal of terpenes is a desirable action that concentrates the oil in the more desirable components, increases its stability by slowing oxidation and resin formation, and increases its solubility in water, ethanol and other solvents used in food technology [5].

Deterpenation of essential oils at large scale is commonly carried out by vacuum distillation and/or extraction with aqueous alcohol or other solvents. The problem in the use of distillation is that the boiling point ranges of oxygenated compounds fraction are typically in between the boiling point ranges of different types of terpenes present [6]. As a consequence, deterpenation by distillation techniques needs to be combined with solvent extraction, or there is risk of loss of quality of the oil due to polymerisation and resinification reactions [7]. Regarding extraction with solvents, a few extractants that have been explored 
at a research level are the following: ethanol, methanol, and their aqueous solutions; and also ethyl acetate and acetone; among others [8-10]. Countercurrent liquid-liquid extraction is also a possibility with pentane being used as a second solvent along with diluted methanol or ethanol. Emerging technologies have also been tested, and for example membrane separation and supercritical fluid extraction are already in industrial use. Membrane separations afford a high quality product due to the operation at low temperatures, along with other concomitant advantages; but they present typical problems of membrane-based processes, such as tendency to clog and maintenance costs $[1,11,12]$. Extraction with supercritical fluids also avoids high temperatures and direct distillation processes in the deterpenation of essential oils, with $\mathrm{CO}_{2}$ being the most commonly employed supercritical fluid, since it is non-toxic, non-flammable, and has a critical temperature of $31{ }^{\circ} \mathrm{C}$; but again, problems inherent to supercritical fluid technologies, such as investment, safety, and operational costs, are a handicap [1,4,13-15].

In the last years, a new approach to the deterpenation of essential oils by solvent extraction has been considered, with the use of ionic liquids instead of conventional volatile solvents $[8,16]$. Ionic liquids are salts that can be used as solvents at the typical operation temperature ranges in liquid-liquid extraction processes, given their low melting point [17]. Since they are integrally constituted by ions, they have a practically negligible volatility at the usual process conditions, and often they also exhibit other interesting properties for their use as solvents: wide liquid range, thermal stability, chemical stability, non-flammability, and great ability to solvate a wide variety of compounds $[17,18]$. Moreover, their properties can be tuned to an important extent by judicious selection and tailoring of the chemical structures of their constitutive ions [17]. This appealing characteristic has led to the coinage of the term 'designer solvents', although applications of ionic liquids in the present moment go far beyond their mere use as solvents [18,19]. Still, their typical set of properties render them very interesting as neoteric solvents in reaction and separation processes, and specifically they can lead to the reconsideration of current solvent extraction processes, as well as envisioning of new ones [20]. For the particular case of deterpenation of essential oils, a series of ionic liquids were tested for the separation of compounds in a simplified, modelled citrus essential oil consisting of a mixture of limonene (a representative terpene) and linalool (a representative oxyterpene) [8,16,21,22]. Although different structural features in the constitutive ions were explored, seeking an optimisation of the ionic liquid to carry out the target separation, the results were only partially successful at best: some of the ionic liquids showed a high separation power of the terpene and the oxyterpene, but at the same time the 
low solubilities of the extracted oxyterpene would imply the need of prohibited amounts of solvent for the implementation of the extraction unit at an industrial scale.

It is the ability to carry out separations according to chemical type, rather than according to physical characteristics (such as vapour pressure), which often makes solvent extraction a so attractive separation technique [23]. In this regard, the main structural difference between limonene and linalool is the presence, in the latter, of a hydroxy group (see chemical structures in Fig. 1). This functional group, contrary to the structural features in limonene, is susceptible of establishing hydrogen bonding with a suitable hydrogen bond acceptor. Thus, a possibility to improve the extracting performance of ionic liquids as extracting solvents in the separation of limonene and linalool could be the use of ionic liquids with a strong capacity to act as hydrogen bond acceptors. Apart from functional groups appended to the cationic core, the ability to accept hydrogen bonding in an ionic liquid is often connected with the basic character of its anion. Therefore, two ionic liquids containing the acetate anion, with a strong basic character, were considered herein: 1-ethyl-3-methylimidazolium acetate $\left(\left[\mathrm{C}_{2} \mathrm{mim}\right][\mathrm{OAc}]\right)$ and 1-butyl-3-methylimidazolium acetate $\left(\left[\mathrm{C}_{4} \mathrm{mim}\right][\mathrm{OAc}]\right)$. Their chemical structures are shown in Fig. 1. In addition to a potentially improved deterpenation of the essential oil and to the general ionic liquid advantages aforementioned, these ionic liquids present further favourable characteristics for their use in the proposed extraction process: moderately low toxicity, relatively low viscosity as compared to other ionic liquids, and the potential to be produced at a competitive cost upon adequate scale up of its production.

In this work, the analysis of the suitability of $\left[\mathrm{C}_{2} \mathrm{mim}\right][\mathrm{OAc}]$ and of $\left[\mathrm{C}_{4} \mathrm{mim}\right][\mathrm{OAc}]$ as solvents for the deterpenation of citrus essential oil has been carried out through the experimental determination of the liquid-liquid equilibrium of each ionic liquid with limonene and linalool. The results have been compared not only with previously tested ionic liquids for the same separation, but also with the benchmark molecular solvents in the stateof-the-art. Moreover, a thermodynamic correlation of the liquid-liquid equilibrium data has been carried out, to facilitate their treatment and implementation in process simulation software. 


\section{Experimental}

\subsection{Materials}

Citrus essential oil was simulated as the mixture of two representatives of its main types of components: the terpene limonene and the oxyterpene linalool. $R$-(+)-Limonene was supplied by Sigma-Aldrich with a nominal purity of $97 \%$, and ( \pm )-linalool was purchased from SAFC with a nominal purity of $\geq 97 \%$. Both chemicals were used as received, without further purification.

The ionic liquid $\left[\mathrm{C}_{2} \mathrm{mim}\right][\mathrm{OAc}]$ was purchased from Iolitec with a nominal purity of $>95 \%$. The ionic liquid [ $\left.\mathrm{C}_{4} \mathrm{mim}\right][\mathrm{OAc}]$ was purchased from Fluka with a nominal purity of $\geq 95 \%$. Both ionic liquids were purified for $48 \mathrm{~h}$ under high vacuum ( $<0.1 \mathrm{mbar}$ ), while continuously stirred and heated at ca. $70{ }^{\circ} \mathrm{C}$, to remove residual volatile compounds that might be present. The chemical identity and absence of major impurities for the purified ionic liquids was verified by proton and carbon nuclear magnetic resonance $\left({ }^{1} \mathrm{H}\right.$ and ${ }^{13} \mathrm{C}$ NMR) spectrometry.

The content in water (a relevant impurity that can particularly affect the properties and performance of ionic liquids [24]) of the substances used in this work was determined by Karl-Fischer titration in a MetrOhm 737 KF coulometer. These values are reported in Table 1 , along with the corresponding CAS numbers and with experimentally determined values of density and refractive index (measured with an Anton Paar DMA 5000 and an ATAGO RX5000 refractometer, respectively), at $298.15 \mathrm{~K}$. These experimental values are compared in Table 1 with literature values published by other authors [25-29]. The fair comparison observed constitutes an additional confirmation of the quality of the batches used in this work.

\subsection{Procedure}

Different ternary mixtures comprising limonene, linalool, and one of the ionic liquids (and also a binary mixture with limonene and each of the ionic liquids) were prepared so that the global compositions lay in the immiscibility domain. These mixtures were placed in jacketed glass cells especially designed for the determination of liquid-liquid equilibria. The cells were capped right after, to avoid losses by evaporation or pickup of moisture. The mixtures were vigorously stirred via magnetic stirring for a minimum of $2 \mathrm{~h}$, at a temperature of $298.15 \pm 0.05 \mathrm{~K}$, controlled with a Selecta Ultraterm 6000383 thermostatic bath. The indicated stirring time was sufficient for the immiscible phases present to be in thermodynamic equilibrium, as determined through a series of tests using different stirring 
times and analysing the composition of the equilibrated phases (see below for details on the compositional analysis procedure). After stopping the stirring, the samples were allowed to settle for at least $12 \mathrm{~h}$, to ensure a complete separation of the phases in equilibrium. Again, preliminary tests showed that this time was enough to guarantee a satisfactory phase separation. Once the phases were completely separated, syringes with attached needles were used to take sample of each phase, without disturbance of the interface (to avoid crosscontamination), for subsequent compositional analysis.

The compositional analysis of the samples was carried out by ${ }^{1} \mathrm{H}$ NMR spectroscopy. This technique has proven to lead to satisfactory results in liquid-liquid equilibria of various types of ternary systems involving ionic liquids [30-34], and in particular in some previous works by us on the deterpenation of essential oils [21,22]. A drop from the samples taken from the equilibrated samples were introduced in NMR tubes, using $\mathrm{CD}_{3} \mathrm{OD}$ (Aldrich, 99.8 atom \% D) as deuteriated solvent. Each tube was immediately capped to avoid losses of volatile components or moisture uptake. The NMR runs were performed at $298 \mathrm{~K}$ in a $7.04 \mathrm{~T}$ Varian Mercury 300 (300 MHz resonance for ${ }^{1} \mathrm{H}$ ) with a coupled robot sampler, using 32 scans and a relaxation time of $20 \mathrm{~s}$, to ensure a good correlation between the areas under the peaks in the NMR spectra and the relative concentrations of hydrogen atoms associated to each peak. The accuracy of the technique was check via the preparation, by weight, of homogeneous mixtures with global composition near the solubility boundary and covering the composition range. For this purpose, a Mettler-Toledo AT261 DeltaRange analytical balance was used to weight the different masses of the components, with a precision of $1 \times 10^{-7} \mathrm{~kg}$. The same procedure and conditions mentioned above were applied to run the NMR spectra of these homogeneous samples. Assignment of the different peaks to the hydrogen atoms in the chemical structures of the compounds was carried out (see Fig. 2), and different sets of peaks were explored for calculation of the compositions of the samples. The set finally selected was the one found to lead to the best agreement between the NMR calculated molar fractions and the known real molar fractions. This set of peaks, following the numbering shown in Fig. 2, included: peaks 18 and 21 for limonene; peaks 9 and the overlapped 8+14 for linalool; and peaks 4 and 5 for the ionic liquid, regardless of being $\left[\mathrm{C}_{2} \mathrm{mim}\right][\mathrm{OAc}]$ or $\left[\mathrm{C}_{4} \mathrm{mim}\right][\mathrm{OAc}]$. Given that more than one peak was chosen for each component, a weighted average (taking into account the number of hydrogen atoms that corresponded to each peak) was obtained in each case to get a single value of area per molecule or ion, prior to calculating the molar fractions. Using this set of peaks, the 
maximum deviations found between the calculated compositions and the real compositions in the homogeneous mixtures prepared by weight were, in molar fraction, 0.006 for the phase rich in essential oil (upper phase) and 0.009 for the phase rich in ionic liquid (lower phase).

\section{Results and discussion}

\subsection{Liquid-liquid equilibria}

Linalool was found to be totally miscible, in any proportion, with [ $\left.\mathrm{C}_{2} \mathrm{mim}\right][\mathrm{OAc}]$ or with [C4mim][OAc], at $298.15 \mathrm{~K}$ and atmospheric pressure. Under these same conditions, a large miscibility gap was observed between limonene and each of the ionic liquids. From these observations, in principle both $\left[\mathrm{C}_{2} \mathrm{mim}\right][\mathrm{OAc}]$ and $\left[\mathrm{C}_{4} \mathrm{mim}\right][\mathrm{OAc}]$ looked like suitable solvents, from a thermodynamic point of view, to carry out the separation of linalool (solute) and limonene (carrier) by liquid-liquid extraction.

The liquid-liquid equilibrium data for the ternary systems limonene + linalool + $\left[\mathrm{C}_{2} \mathrm{mim}\right][\mathrm{OAc}]$ and limonene + linalool $+\left[\mathrm{C}_{4} \mathrm{mim}\right][\mathrm{OAc}]$, determined experimentally at 298.15 K and atmospheric pressure, are shown in Table 2. In accordance with the qualitative observations on miscibility of pairs of compounds discussed above, there is a tie-line in each ternary system for which the composition of linalool is zero in both phases, corresponding to the binary mixture limonene + ionic liquid. An interesting feature directly inferred from inspection of the data is that, in most experimental tie-lines of any of the two systems, no ionic liquid was detected in the top phase. This is similar to what was previously found in liquid-liquid equilibria of analogous ternary systems with other ionic liquids [21,22].

A better perspective of the meaning of the liquid-liquid equilibrium data sets is provided by the equilateral triangular diagrams plotted in Fig. 3. Both systems correspond to a Type 1 system, according to the classification by Sørensen et al. [35], since there is only one immiscible pair of compounds and two totally miscible pairs. Both diagrams are quite similar, with tie-lines of positive slope and with the plait point (the composition at which both ends of the tie-line have a coincident composition located closer to the vertex representing limonene. Still, some differences are observed, which are of course related to the only structural difference in the components of the systems: the length of the alkyl side chain in the cation of the ionic liquid. By comparing the tie-lines of the binary limonene + ionic liquid, it is observed that limonene is more soluble in $\left[\mathrm{C}_{4} \mathrm{mim}\right][\mathrm{OAc}]$ than in $\left[\mathrm{C}_{2} \mathrm{mim}\right][\mathrm{OAc}]$; and in general, the size of the immiscibility region is a little smaller in the system with [C4mim][OAc]. This is due to a greater affinity of the latter ionic liquid for the components 
of the model essential oil. In particular, the reason of this greater affinity lies in the longer hydrocarbon alkyl chain of the $\left[\mathrm{C}_{4} \mathrm{mim}\right]^{+}$cation, which confers a relatively more apolar character to the ionic liquid.

\subsection{Distribution ratios and selectivities}

Two classical parameters are often used to evaluate the performance, from a thermodynamic perspective, of a solvent in a liquid-liquid extraction process: the solute distribution ratio $(\beta)$ and the selectivity $(S)$. These can be directly calculated from the liquidliquid equilibrium data, according to the following expressions:

$$
\begin{aligned}
& \beta=\frac{x_{2}^{I I}}{x_{2}^{I}} \\
& S=\frac{x_{2}^{I I}}{x_{2}^{I}} \cdot \frac{x_{1}^{I}}{x_{1}^{I I}}
\end{aligned}
$$

where $x$ is molar fraction, subscripts 1 and 2 represent the carrier (limonene) and the solute (linalool), and superscripts $I$ and $I I$ represent the essential oil-rich and ionic liquid-rich phases, respectively. The solute distribution ratio refers to the transfer of the solute (in this work, linalool) from the feed to the solvent phase, and gives a measure of the amount of solvent that would be needed to carry out the extraction (the lower the solute distribution ratio, the larger amount of solvent that would be needed). The selectivity can be interpreted as the quotient of two distribution ratios: the one of the solute divided by the one of the carrier. It provides a measure of the separating power of the solvent, and would be connected, in terms of design, with the number of stages necessary to achieve a desired degree of separation (the lower the selectivity, the larger the number of stages needed). Therefore, a good solvent would ideally be the one leading to high solute distribution ratios and high selectivities for the targeted separation.

The calculated solute distribution ratios and selectivities in the systems studied herein are reported in Table 2, along with the experimental liquid-liquid equilibrium data. As it is evident from the positive slopes observed for the tie-lines in the diagrams of Fig. 3, all values of solute distribution ratios are greater than the unity, indicating a preference of the linalool for the ionic liquid phase. A graphical comparison of $\beta$ and $S$ values for the two studied systems is provided in Fig. 4. For the lower tie-lines, the system with [ $\left.\mathrm{C}_{4} \mathrm{mim}\right][\mathrm{OAc}]$ performs notably better. When more linalool is present in the system, somewhat higher values are obtained for the system with $\left[\mathrm{C}_{2} \mathrm{mim}\right][\mathrm{OAc}]$. 
With regard to other ionic liquids previously investigated to carry out the separation of limonene and linalool by solvent extraction, Fig. 5 establishes a comparison of the solute distribution ratios and selectivities obtained for the acetate ionic liquids in this work with those so far obtained for the most satisfactory ionic liquids to date: 1-ethyl-3methylimidazolium methanesulfonate ([C $\left.\left.\mathrm{C}_{2} \mathrm{mim}\right][\mathrm{OMs}]\right)$ and 1-ethyl-3-methylimidazolium ethylsulfate $\left(\left[\mathrm{C}_{2} \mathrm{mim}\right]\left[\mathrm{EtSO}_{4}\right]\right)[8,16]$. This comparison was made using the parameters defined in a mass basis, $\beta_{w}$ and $S_{w}$, as defined by:

$$
\begin{aligned}
& \beta_{w}=\frac{w_{2}^{I I}}{w_{2}^{I}} \\
& S_{w}=\frac{w_{2}^{I I}}{w_{2}^{I}} \cdot \frac{w_{1}^{I}}{w_{1}^{I I}}
\end{aligned}
$$

where $w$ stands for mass fraction and all other symbols have the same meaning as in equations 1 and 2. The use of these mass-based parameters looks like a fairer comparison from a perspective of practical application, where the mass of ionic liquid and not its number of moles will be relevant. As seen in Fig. 5, the acetate ionic liquids tested herein present, as compared to the other ionic liquids, very high solute distribution ratios and relatively high selectivities, in particular in the range of low concentration of linalool in the essential oil-rich phase. This is a region of particular interest, since the initial concentration of oxyterpenes (linalool) in the essential oil lies within it. From Fig. 5b, it can be inferred that the selectivities achieved with [ $\left.\mathrm{C}_{2} \mathrm{mim}\right][\mathrm{OMs}]$ are higher than with the acetates for any concentration; however, the low distribution ratios associated (Fig. 5a) would prevent its use in a scaled up deterpenation process. In addition, this is a subcooled ionic liquid at $298.15 \mathrm{~K}$ in pure state (its melting temperature is somewhat higher), which could additionally lead to undesired crystallisation problems in the real process. Hence, it can be said that, in general terms, and from a thermodynamic perspective, the acetate ionic liquids outperform all other ionic liquids investigated to date. For a first deterpenation step, in the region with low concentrations of linalool, the acetate ionic liquids would be great solvents. For further deterpenation beyond the maximum capacity of these ionic liquids, perhaps vacuum distillation would be preferred.

With the exception of $\left[\mathrm{C}_{4} \mathrm{mim}\right][\mathrm{OAc}]$, all other ionic liquids compared in Fig. 5 have exactly the same cation. Therefore, the difference observed in their performance has to be directly related to their anion. The acetate anion in $\left[\mathrm{C}_{2} \mathrm{mim}\right][\mathrm{OAc}]$ (and in [ $\left.\mathrm{C}_{4} \mathrm{mim}\right][\mathrm{OAc}]$ ) has a pronounced basic character, if compared to the $[\mathrm{OMs}]^{-}$and $\left[\mathrm{EtSO}_{4}\right]^{-}$anions. This 
basicity may play a key role in establishing hydrogen bonds or a similar interaction with the hydroxy group present in the oxyterpene structure, thus favouring its affinity for the ionic liquid phase.

A similar behaviour to that observed in Fig. 5 is also observed when the comparison is carried out not just with ionic liquid but with other molecular solvents previously tested [36,37]. Among the latter, ethylene glycol and a 15:85 wt/wt mixture of water and ethanol were found to be the best benchmarks. In Fig. 6, again the solute distribution ratio and selectivity values are higher for the systems with the acetate ionic liquids in the region of low concentration of linalool. Therefore, both $\left[\mathrm{C}_{2} \mathrm{mim}\right][\mathrm{OAc}]$ and $\left[\mathrm{C}_{4} \mathrm{mim}\right][\mathrm{OAc}]$ can outperform any of the reference solvents for the concentration of citrus essential oil in oxyterpenes.

\subsection{Data correlation}

A correlation of the liquid-liquid equilibrium data sets of the two ternary systems investigated was carried out. Two classical models were selected: the NRTL ("Non-Random Two-Liquid”) and UNIQUAC (“UNIversal QUAsi-Chemical”) models [38,39]. These correlation models were originally developed for systems with no electrolytes. Although multiple modifications of these methods to work with electrolyte-containing mixtures exist, the classical formulations of the models have already been reported to satisfactorily correlate liquid-liquid equilibrium data of ternary systems containing ionic liquids (see, for instance, references 8, 21, 30-32, and references therein).

A computer program by Sørensen and Arlt was used for the correlation of the data with both models [40]. The algorithm in this program uses two objective functions: a first one, $F_{a}$, which is a function of activities and does not require the estimation of any previous parameters; and a second one, $F_{b}$, which is a function of compositions and takes the set of parameters resulting from the convergence with $F_{a}$ as initial guess to fit the experimental concentrations. The mathematical expressions of these two objective functions are:

$$
\begin{aligned}
& F_{a}=\sum_{k} \sum_{i}\left(\frac{a_{i k}^{I}-a_{i k}^{I I}}{a_{i k}^{I}+a_{i k}^{I I}}\right)^{2}+Q \sum_{n} P_{n}^{2} \\
& F_{b}=\sum_{k} \min \sum_{i} \sum_{j}\left(x_{i j k}-\hat{x}_{i j k}\right)^{2}+Q \sum_{n} P_{n}^{2}+\left[\ln \left(\frac{\hat{\gamma}_{S \infty}^{I}}{\hat{\gamma}_{S \infty}^{I I}} \beta_{\infty}\right)\right]^{2}
\end{aligned}
$$

where $a$ is activity, $x$ is molar fraction, "min" refers to a minimum obtained by the NelderMead method [41], $\gamma_{\text {So }}$ represents the solute activity coefficient at infinite dilution, and the symbol $\wedge$ on top of a variable indicates that it is a calculated value. Superscripts $I$ y $I I$ refer to 
the phases in equilibrium, and subscripts $i, j$ and $k$ refer to the components, the phases and the tie-lines, respectively. Both functions include a penalisation term (second term on the right hand side of the equations) to reduce the risk of multiple solutions associated with large values of the parameters. In this penalisation term, $Q$ is an empirical constant, which was assigned the value of $10^{-6}$ in $F_{a}$ and the value of $10^{-10}$ in $F_{b}$; and $P_{n}$ are the adjustable parameters (binary interaction parameters of the corresponding correlation model). The expression of $F_{b}$ also includes an additional term (third term on the right hand side of the equation) intended to contribute to a more accurate reproduction of the solute distribution ratio at the particularly interesting case of small concentrations of solute in the system. This term is only considered if a fixed value for the molar distribution ratio of the solute at infinite dilution, $\beta_{\infty}$, is previously defined by the program user; otherwise, the last term in equation 6 is zero.

For application of the UNIQUAC model, the structural parameters $r$ and $q$ of the species involved are needed. These parameters, shown in Table 3, in the case of the ionic liquids were calculated from group contribution data [42-44]. For application of the NRTL model, three different correlations were made for each data set with three different values of the nonrandomness parameter, $\alpha$, of the model: $0.1,0.2$ and 0.3 . These are typical values within the expected range of values of $\alpha$ [38].

The quality of the correlations was assessed by means of the residual function $F$ and the mean error of the solute distribution ratio, $\Delta \beta$, defined by the following expressions:

$$
\begin{aligned}
& F=100 \times\left[\sum_{k} \min \sum_{i} \sum_{j} \frac{\left(x_{i j k}-\hat{x}_{i j k}\right)^{2}}{6 M}\right]^{0.5} \\
& \Delta \beta=100 \times\left[\frac{1}{M} \sum_{k}\left(\frac{\beta_{k}-\hat{\beta}_{k}}{\beta_{k}}\right)^{2}\right]^{0.5}
\end{aligned}
$$

where $M$ is the total number of tie-lines, and all other variables and symbols have already been defined.

Two different correlation strategies were used for each case, in a similar manner to the procedure described by Sørensen [40], and taking advantage of the potentialities of the software used. In a first situation, the correlation was performed without fixing a previous value for $\beta \infty$. In a second approach, an optimal value of this parameter was found by trial and 
error with the minimisation of $\Delta \beta$ as the optimality criterion, and this value of $\beta_{\infty}$ was fixed prior to carrying out the correlation.

The values of $F$ and $\Delta \beta$ for correlation of the liquid-liquid equilibrium data sets with the NRTL model (showing only the results with $\alpha=0.3$, since this value of the nonrandomness parameter led to a better correlation than the other two tried) and the UNIQUAC model, both fixing and without fixing a previous value of $\beta \propto$, are shown in Table 4. It is evident that the NRTL model provides a better correlation of the data than the UNIQUAC model. However, the NRTL correlation without fixing a previous value of $\beta_{\infty}$ leads to rather high values of $\Delta \beta$. This aspect can be improved substantially with the use of a previously set value for $\beta_{\infty}$, although this is at the cost of increasing the value of the residual function $F$. Nevertheless, since the deviation of the correlation with the experimental data, as given by $F$, still remained below the $1 \%$, the NRTL model with $\alpha=0.3$ and a previously fixed value of $\beta_{\infty}$ was selected as the preferred correlation. The corresponding binary interaction parameters obtained for this particular case, for both studied ternary systems, are shown in Table 5. Since the model was originally developed for non-electrolyte systems, it makes no sense to infer any physical meaning, in terms of interactions between pairs of compounds, from the sets of binary interaction parameters obtained. In spite of this, it is worth emphasising how there was no need of using an electrolyte-adapted NRTL version to get a good correlation of the data, thus allowing a continuous mathematical description of the discrete liquid-liquid equilibrium data experimentally determined.

In the triangular diagrams of Fig. 3, the experimental tie-lines and the corresponding correlated tie-lines, calculated with the NRTL model ( $\alpha=0.3$ ) fixing an optimised value of $\beta_{\propto}$, are plotted together for direct visual comparison. The good agreement observed between both sets of tie-lines further corroborates the quality of the correlations obtained. From the compositions of the correlated tie-lines, the corresponding correlated values of $\beta$ and $S$ were calculated (with equations 1 and 2), and lines connecting these values have been added to the plots in Fig. 4, enabling a direct visual comparison with the experimental values.

\section{Conclusions}

The ionic liquids $\left[\mathrm{C}_{2} \mathrm{mim}\right][\mathrm{OAc}]$ and $\left[\mathrm{C}_{4} \mathrm{mim}\right][\mathrm{OAc}]$ are suitable solvents for the deterpenation of citrus essential oil, according to liquid-liquid equilibrium data experimentally determined using a modelled essential oil constituted by limonene and linalool. This is likely a result of the preferential interaction that the (hydrogen accepting) 
acetate anions can establish with the (hydrogen donating) hydroxyle group of the linalool. In addition, these ionic liquids present other interesting properties as solvents for liquid-liquid extraction processes, such as practically negligible volatility, non-flammability, and moderately low toxicity.

At low concentrations of linalool in the system, as it can be the case in the initial stage of deterpenation of an essential oil (which contains about $3 \%$ of oxyterpenes), these two acetate ionic liquids perform better, to the best of our knowledge, and in terms of solute distribution ratio and selectivity, than any other solvent tested to date (either molecular solvents or other ionic liquids) for the deterpenation of essential oils. The results are somewhat better for [C4mim][OAc] than for [ $\left.\mathrm{C}_{2} \mathrm{mim}\right][\mathrm{OAc}]$, although a final decision between them should also include other variables, such as cost, toxicity... or, in general, considerations related to their life cycle.

The liquid-liquid equilibrium data reported for the ternary systems limonene + linalool + ([C $\left.\mathrm{C}_{2} \mathrm{mim}\right][\mathrm{OAc}]$ or $\left.\left[\mathrm{C}_{4} \mathrm{mim}\right][\mathrm{OAc}]\right)$ at $298.15 \mathrm{~K}$ and atmospheric pressure could be suitably correlated by means of classical thermodynamic models such as NRTL or UNIQUAC. In particular, the NRTL model was found to lead to the best results, with a nonrandomness parameter $\alpha=0.3$ and a previously optimised and fixed value for the solute distribution ratio at infinite dilution. The correlations carried out transform the discrete information of the experimental tie-lines into a continuous mathematical description of the liquid-liquid equilibrium in the systems, facilitating its computerised treatment in e.g. commercial software packages for process simulation.

A further aspect to get a more reliable idea of the feasibility of the process proposed herein would include the analysis of the recovery, in an efficient manner, of the ionic liquid solvent from the raffinate and extract streams. Although in principle this is possible and easy as a result of the infinite relative volatility existing between the molecular volatile components of the essencial oil and the non-volatile ionic liquid, the study of vapour-liquid equilibria of the systems involved would provide a quantitative perspective of the energy needed, or the vacuum to be applied, in the auxiliary solvent recovery units of the solvent extraction deterpenation process.

\section{Acknowledgements}

The authors acknowledge the Ministry of Economy and Competitiveness of Spain for financial support through project CQT2012-33359 (including European Regional Development Fund advanced funding), and through the Ramón y Cajal program (H.R.). 


\section{References}

[1] A. Arce, A. Soto, in: N. Benkeblia, P. Tennant (Eds.), Tree and Forestry Science and Biotechnology, Special Issue 1, vol. 2, Global Sciences Books, London, 2009, pp. 19.

[2] J. Lawless, The Encyclopedia of Essential Oils, Harper Collins, London, 2002.

[3] A. Verzera, A. Trozzi, G. Dugo, G. Di Bella, A. Cotroneo, Flavour Fragr. J. 19 (2004) 544-548.

[4] M. Kondo, M. Goto, A. Kodama, T. Hirose, Ind. Eng. Chem. Res. 39 (2000) 47454748.

[5] J. Owusu-Yaw, R. F. Matthews, P. F. West, J. Food Sci. 51 (1986) 1180-1182.

[6] G. R. Stuart, D. Lopes, J. V. Oliveira, J. Am. Oil Chem. Soc. 78 (2001) 1041-1044.

[7] A. Fleisher, G. Biza, N. Secord, J. Dono, Perfumer and Flavorist 12 (1987) 57-61.

[8] A. Arce, A. Marchiaro, O. Rodríguez, A. Soto, AIChE J. 52 (2006) 2089-2097; and references therein.

[9] M. B. Gramajo de Doz, A. M. Cases, H. N. Sólimo, J. Chem. Thermodyn. 40 (2008) 1575-1579.

[10] L. M. Sevgili, S. Sahin, S. Ismail Kirbaslar, J. Chem. Eng. Data 53 (2008) 737-741.

[11] D. J. Brose, M. B. Chidlaw, D. T. Friesen, E. D. LaChapelle, P. van Eikeren, Biotechnol. Prog. 11 (1995) 214-220.

[12] K. Sakamoto, K. Fujii, A. Inoue, H. Kozuka, H. Ohta, Food Sci. Technol. Res. 9 (2003) 11-16.

[13] S. Diaz, S. Espinosa, E. A. Brignole, J. Supercrit. Fluids 35 (2005) 49-61.

[14] F. Gironi, M. Maschietti, Chem. Eng. Sci. 63 (2008) 651-661.

[15] F. Benvenuti, F. Gironi, L. Lamberti, J. Supercrit. Fluids 20 (2001) 29-44.

[16] A. Arce, A. Pobudkowska, O. Rodríguez, A. Soto, Chem. Eng. J. 133 (2007) 213218.

[17] A. Stark, K. R. Seddon, in: A. Seidel (Ed.), Kirk-Othmer Encyclopedia of Chemical Technology, vol. 26, Wiley, Hoboken, NJ, 2007.

[18] M. Freemantle, An Introduction to Ionic Liquids, The Royal Society of Chemistry, Cambridge, 2010.

[19] J. F. Brennecke, R. D. Rogers, K. R. Seddon (eds.), Ionic liquids IV - Not just solvents anymore, ACS Symposium Series 975, American Chemical Society, Washington, DC, 2007. 
[20] S. Werner, M. Haumann, P. Wasserscheid, Annu. Rev. Chem. Biomol. Eng. 1 (2010) 203-230.

[21] S. Lago, H. Rodríguez, A. Soto, A. Arce, J. Chem. Eng. Data 56 (2011) 1273-1281; and references therein.

[22] S. Lago, H. Rodríguez, A. Soto, A. Arce, Sep. Sci. Technol. 47 (2012) 292-299.

[23] R. E. Treybal, Liquid extraction, McGraw-Hill, $2^{\text {nd }}$ ed., New York, 1963.

[24] K. R. Seddon, A. Stark, M. J. Torres, Pure Appl. Chem. 72 (2000) 2275-2287.

[25] J. A. Riddick, W. B. Bunger, T. K. Sakano, Organic Solvents - Physical Properties and Methods of Purification, Wiley, $4^{\text {th }}$ ed., New York, 1986.

[26] F. Comelli, S. Ottani, J. Chem. Eng. Data 47 (2002) 93-97.

[27] R. Francesconi, C. Castellari, J. Chem. Eng. Data 46 (2001) 1520-1525.

[28] M. G. Freire, A. R. R. Teles, M. A. A. Rocha, B. Schröder, C. M. S. S. Neves, P. J. Carvalho, D. V. Evtuguin, L. M. N. B. F. Santos, J. A. P. Coutinho, J. Chem. Eng. Data 56 (2011) 4813-4822.

[29] M. Tariq, P. A. S. Forte, M. F. Costa Gomes, J. N. Canongia Lopes and L. P. N. Rebelo, J. Chem. Thermodyn. 41 (2009) 790-798.

[30] A. Arce, O. Rodríguez, A. Soto, Ind. Eng. Chem. Res. 43 (2004) 8323-8327.

[31] U. Domańska, A. Pobudkowska, Z. Żołek-Tryznowska, J. Chem. Eng. Data 52 (2007) 2345-2349.

[32] A. Arce, M. J. Earle, H. Rodríguez, K. R. Seddon, J. Phys. Chem. B 111 (2007) $4732-4736$.

[33] T. Banerjee, K. K. Verma, A. Khanna, AIChE J. 54 (2008) 1874-1885.

[34] U. Domańska, Z. Żołek-Tryznowska, A. Pobudkowska, J. Chem. Eng. Data 54 (2009) 972-976.

[35] J. M. Sørensen, T. Magnussen, P. Rasmussen, A. Fredenslund, Fluid Phase Equilib. 2 (1979) 297-309.

[36] A. Arce, A. Marchiaro, O. Rodríguez, A. Soto, Chem. Eng. J. 89 (2002) 223-227.

[37] A. Arce, A. Marchiaro, J. M. Martínez-Ageitos, A. Soto, Can. J. Chem. Eng. 83 (2005) 366-370.

[38] H. Renon, J. M. Prausnitz, AIChE J. 14 (1968) 135-144.

[39] D. S. Abrams, J. M. Prausnitz, AIChE J. 21 (1975) 116-128.

[40] J. M. Sørensen, W. Arlt, Liquid-Liquid Equilibrium Data Collection, DECHEMA Chemistry Data Series, Frankfurt, 1980.

[41] J. A. Nelder, R. Mead, Comp. J. 7 (1965) 308-313. 
[42] A. Bondi, Physical Properties of Molecular Crystals, Liquids and Glasses, Wiley, New York, 1968.

[43] R. Kato, J. Gmehling, J. Chem. Thermodyn. 37 (2005) 603-619.

[44] Z. Lei, J. Zhang, Q. Li, B. Chen, Ind. Eng. Chem. Res. 48 (2009) 2697-2704. 


\section{Figure captions}

Fig. 1. Chemical structures of the components of the modelled citrus essential oil, and of the ionic liquids tested as extracting solvents for deterpenation: a) limonene, b) linalool, c) $\left[\mathrm{C}_{2} \mathrm{mim}\right][\mathrm{OAc}]$, d) $\left[\mathrm{C}_{4} \mathrm{mim}\right][\mathrm{OAc}]$.

Fig. 2. Example of ${ }^{1} \mathrm{H}$ NMR spectrum for a ternary mixture of limonene, linalool and [ $\left.\mathrm{C}_{2} \mathrm{mim}\right][\mathrm{OAc}]$, showing the assignment of peaks to hydrogen atoms in the chemical structures of the compounds.

Fig. 3. Experimental tie-lines (solid circles, solid lines), and their corresponding correlated tie-lines obtained with the NRTL model ( $\alpha=0.3$ ) with a previously fixed value of $\beta_{\infty}$ (open circles, dashed lines), for the ternary systems limonene + linalool + ionic liquid, at 298.15 K



Fig. 4. Experimental values of a) the solute distribution ratio $(\beta)$ and b) the selectivity $(S)$, as a function of the molar fraction of linalool in the limonene-rich phase ( $\left.x_{\text {linalool}}\right)$, for the systems limonene + linalool $+\left[\mathrm{C}_{2} \mathrm{mim}\right][\mathrm{OAc}]$ (triangles) and limonene + linalool + [C4mim][OAc] (squares), at $298.15 \mathrm{~K}$ and atmospheric pressure. The correlated values obtained with the NRTL model ( $\alpha=0.3$ ) fixing $\beta_{\infty}$ are plotted as solid lines for the system with $\left[\mathrm{C}_{2} \mathrm{mim}\right][\mathrm{OAc}]$ and as dashed lines for the system with [ $\left.\mathrm{C}_{4} \mathrm{mim}\right][\mathrm{OAc}]$.

Fig. 5. Experimental values of a) the solute distribution ratio $\left(\beta_{w}\right)$ and b) the selectivity $\left(S_{w}\right)$, in a mass fraction basis, as a function of the mass fraction of linalool in the limonene-rich phase ( $w_{\text {linalool}}$ ), for the systems limonene + linalool $+\left[\mathrm{C}_{2} \mathrm{mim}\right][\mathrm{OMs}]$ (open circles), ${ }^{8}$ limonene + linalool $+\left[\mathrm{C}_{2} \mathrm{mim}\right]\left[\mathrm{EtSO}_{4}\right]$ (open diamonds), ${ }^{16}$ limonene + linalool + $\left[\mathrm{C}_{2} \mathrm{mim}\right][\mathrm{OAc}]$ (solid triangles), and limonene + linalool $+\left[\mathrm{C}_{4} \mathrm{mim}\right][\mathrm{OAc}]$ (solid squares), at 298.15 K and atmospheric pressure.

Fig. 6. Experimental values of a) the solute distribution ratio $\left(\beta_{w}\right)$ and b) the selectivity $\left(S_{w}\right)$, in a mass fraction basis, as a function of the mass fraction of linalool in the limonene-rich phase ( $w$ linalool), for the systems limonene + linalool + diethylene glycol (open hexagons), ${ }^{36}$ limonene + linalool $+\left(15: 85 \mathrm{wt} / \mathrm{wt}\right.$ mixture of water + ethanol) (inverted triangles), ${ }^{37}$ limonene + linalool $+\left[\mathrm{C}_{2} \mathrm{mim}\right][\mathrm{OAc}]$ (solid triangles) and limonene + linalool + [C $\left.{ }_{4} \mathrm{mim}\right][\mathrm{OAc}]$ (solid squares), at $298.15 \mathrm{~K}$ and atmospheric pressure. 
Table 1. CAS number, experimental water content $\left(w_{\mathrm{H} 2 \mathrm{O}}\right)$, and experimental and literature values (references 25-29) for density $(\rho)$ and refractive index $\left(n_{D}\right)$, at $298.15 \mathrm{~K}$ and atmospheric pressure, for the compounds used in this work. ${ }^{a}$

\begin{tabular}{llccccc}
\hline & & $w_{\text {H2O }}(\%)$ & \multicolumn{2}{c}{$\rho\left(\mathrm{g} \mathrm{cm}^{-3}\right)$} & \multicolumn{2}{c}{$n_{D}$} \\
\cline { 3 - 7 } Compound & CAS number & Exp. & Exp. & Lit. & Exp. & Lit. \\
\hline limonene & $5989-27-5$ & 0.02 & 0.83868 & $0.8383^{[25]}$ & 1.47081 & $1.4701^{[25]}$ \\
linalool & $78-70-6$ & 0.02 & 0.85683 & $0.85760^{[26]}$ & 1.45961 & $1.460^{[27]}$ \\
{$\left[C_{2}\right.$ mim][OAc] } & $143314-17-4$ & 0.12 & 1.09902 & $1.0993^{[28]}$ & 1.50069 & $1.50091^{[28]}$ \\
{$\left[C_{4}\right.$ mim][OAc] } & $284049-75-8$ & 0.21 & 1.05270 & $1.0532^{[29]}$ & 1.49372 & $1.49381^{[29]}$ \\
\hline
\end{tabular}

a Standard uncertainties $u$ are: $u(T)=0.01 \mathrm{~K}, u(p)=10 \mathrm{kPa}$ and the combined expanded uncertainty $U_{c}$ is $U_{c}(\rho)=0.00001 \mathrm{~g} \mathrm{~cm}^{-3}$ (0.95 level of confidence); $u(T)=0.02 \mathrm{~K}, u(p)=10 \mathrm{kPa}$ and the combined expanded uncertainty $U_{c}$ is $U_{c}\left(\mathrm{n}_{\mathrm{D}}\right)=0.00004$ (0.95 level of confidence). 
Table 2. Composition of the experimental tie-line ends, solute distribution ratio $(\beta)$, and selectivity $(S)$, for the ternary systems limonene + linalool $+\left(\left[\mathrm{C}_{2} \mathrm{mim}\right][\mathrm{OAc}]\right.$ or [C4mim][OAc]) at $298.15 \mathrm{~K}$ and atmospheric pressure. Superscripts $I$ and $I I$ refer to the limonene-rich phase and to the ionic liquid-rich phase, respectively. The molar fractions of limonene, linalool and ionic liquid are represented by $x_{1}, x_{2}$ and $x_{3}$, respectively. ${ }^{a}$

\begin{tabular}{|c|c|c|c|c|c|c|c|}
\hline \multicolumn{3}{|c|}{ Ionic liquid-rich phase } & \multicolumn{3}{|c|}{ Limonene-rich phase } & \multirow{2}{*}{$\beta$} & \multirow{2}{*}{$S$} \\
\hline$x_{1}^{I I}$ & $x_{2}^{I I}$ & $x_{3}{ }^{I I}$ & $x_{1}^{I}$ & $x_{2}^{I}$ & $x_{3}^{I}$ & & \\
\hline \multicolumn{8}{|c|}{ limonene + linalool $+\left[\mathrm{C}_{2} \mathrm{mim}\right][\mathrm{OAc}]$} \\
\hline 0.044 & 0.000 & 0.956 & 1.000 & 0.000 & 0.000 & --- & --- \\
\hline 0.047 & 0.038 & 0.915 & 0.994 & 0.006 & 0.000 & 6.33 & 134 \\
\hline 0.057 & 0.090 & 0.853 & 0.988 & 0.012 & 0.000 & 7.50 & 130 \\
\hline 0.097 & 0.212 & 0.691 & 0.981 & 0.019 & 0.000 & 11.2 & 113 \\
\hline 0.152 & 0.279 & 0.569 & 0.973 & 0.027 & 0.000 & 10.3 & 66.2 \\
\hline 0.338 & 0.319 & 0.343 & 0.963 & 0.035 & 0.002 & 9.11 & 26.0 \\
\hline 0.551 & 0.229 & 0.220 & 0.901 & 0.070 & 0.029 & 3.27 & 5.35 \\
\hline \multicolumn{8}{|c|}{ limonene + linalool $+\left[\mathrm{C}_{4} \mathrm{mim}\right][\mathrm{OAc}]$} \\
\hline 0.067 & 0.000 & 0.933 & 1.000 & 0.000 & 0.000 & --- & --- \\
\hline 0.071 & 0.019 & 0.910 & 0.999 & 0.001 & 0.000 & 19.0 & 267 \\
\hline 0.093 & 0.106 & 0.801 & 0.995 & 0.005 & 0.000 & 21.2 & 227 \\
\hline 0.169 & 0.198 & 0.633 & 0.992 & 0.008 & 0.000 & 24.8 & 145 \\
\hline 0.226 & 0.225 & 0.549 & 0.989 & 0.011 & 0.000 & 20.4 & 89.5 \\
\hline 0.479 & 0.237 & 0.284 & 0.959 & 0.030 & 0.011 & 7.90 & 15.8 \\
\hline 0.667 & 0.163 & 0.170 & 0.917 & 0.052 & 0.031 & 3.13 & 4.31 \\
\hline
\end{tabular}

a Standard uncertainties $u$ are: $u(T)=0.05 \mathrm{~K}, u(x)=0.009$ in the ionic liquid-rich phase, $u(x)$ $=0.006$ in the limonene-rich phase, and $u(p)=10 \mathrm{kPa}$. 
Table 3. Structural parameters $r$ and $q$ of the UNIQUAC model, for the compounds involved in the ternary systems limonene + linalool $+\left(\left[\mathrm{C}_{2} \mathrm{mim}\right][\mathrm{OAc}]\right.$ or $\left.\left[\mathrm{C}_{4} \mathrm{mim}\right][\mathrm{OAc}]\right)$. In the case of the ionic liquids, the values of $r$ and $q$ were obtained via a group contribution procedure.

\begin{tabular}{lccc}
\hline Compound & $r$ & $q$ & Ref. \\
\hline limonene & 6.2783 & 5.2080 & 42 \\
linalool & 7.0356 & 6.0600 & 42 \\
{$\left[\mathrm{C}_{2}\right.$ mim][OAc] } & 6.0191 & 5.5760 & 43,44 \\
{$\left[\mathrm{C}_{4}\right.$ mim][OAc] } & 7.3291 & 6.9960 & 43,44 \\
\hline
\end{tabular}


Table 4. Residual function $F$, and mean error of the solute distribution ratio, $\Delta \beta$, for the correlation of the experimental liquid-liquid equilibrium data of the ternary systems limonene + linalool $+\left(\left[\mathrm{C}_{2} \mathrm{mim}\right][\mathrm{OAc}]\right.$ or $\left.\left[\mathrm{C}_{4} \mathrm{mim}\right][\mathrm{OAc}]\right)$, at $298.15 \mathrm{~K}$ and atmospheric pressure, with the NRTL and UNIQUAC models, fixing and without fixing a priori the solute distribution ratio at infinite dilution, $\beta_{\infty}$.

\begin{tabular}{llccc}
\hline Ionic liquid & Model & $\beta_{\infty}$ & $F$ & $\Delta \beta$ \\
\hline$\left[\mathrm{C}_{2}\right.$ mim][OAc] & NRTL $(\alpha=0.3)$ & - & 0.7924 & 84.7 \\
& & 3.57 & 0.8741 & 15.8 \\
& UNIQUAC & - & 1.9718 & 595 \\
& & 1.80 & 1.4989 & 16.4 \\
\hline$\left[\mathrm{C}_{4}\right.$ mim][OAc] & NRTL $(\alpha=0.3)$ & - & 0.5817 & 40.0 \\
& & 33.3 & 0.8335 & 26.7 \\
& \multirow{2}{*}{ UNIQUAC } & - & 0.7994 & 273 \\
& & 40.0 & 0.8892 & 28.2 \\
\hline
\end{tabular}


Table 5. Binary interaction parameters $\left(\Delta g_{i j}, \Delta g_{j i}\right)$ for the correlation of the experimental liquid-liquid equilibrium data of the ternary systems limonene (1) + linalool (2) + ([C $\left.\mathrm{C}_{2} \mathrm{mim}\right][\mathrm{OAc}]$ or [ $\left.\left.\mathrm{C}_{4} \mathrm{mim}\right][\mathrm{OAc}]\right)$ (3) at $298.15 \mathrm{~K}$ and atmospheric pressure, by means of the NRTL ( $\alpha=0.3$ ) model and previously fixing a value for $\beta \infty$.

\begin{tabular}{llccc}
\hline Ionic liquid & Model & Components & $\Delta g_{i j} /\left(\mathrm{J} \cdot \mathrm{mol}^{-1}\right)$ & $\Delta g_{j i} /\left(\mathrm{J} \cdot \mathrm{mol}^{-1}\right)$ \\
\hline$\left[\mathrm{C}_{2}\right.$ mim] $[\mathrm{OAc}]$ & NRTL & $1-2$ & 3260.0 & 4528.1 \\
& $\left(\alpha=0.3, \beta_{\infty}=3.57\right)$ & $1-3$ & 14732 & 7518.3 \\
& & $2-3$ & -3914.4 & 9349.6 \\
\hline$\left[\mathrm{C}_{4}\right.$ mim] $[\mathrm{OAc}]$ & $\mathrm{NRTL}$ & $1-2$ & 2509.2 & 6288.1 \\
& $\left(\alpha=0.3, \beta_{\infty}=33.3\right)$ & $1-3$ & 13894 & 5773.6 \\
& & $2-3$ & -5350.8 & 7329.3 \\
\hline
\end{tabular}




\section{Figure 1}

a)

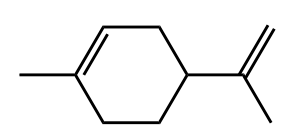

b)

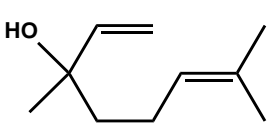

c)

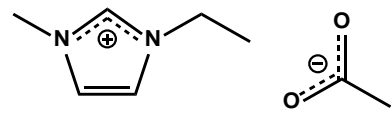

d)

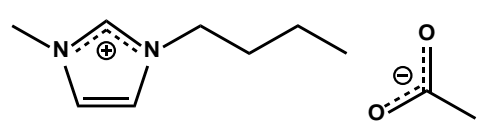

Fig. 1. Chemical structures of the components of the modelled citrus essential oil, and of the ionic liquids tested as extracting solvents for deterpenation: a) limonene, b) linalool, c) [C $2 \mathrm{mim}][\mathrm{OAc}], \mathrm{d})\left[\mathrm{C}_{4} \mathrm{mim}\right][\mathrm{OAc}]$. 


\section{Figure 2}

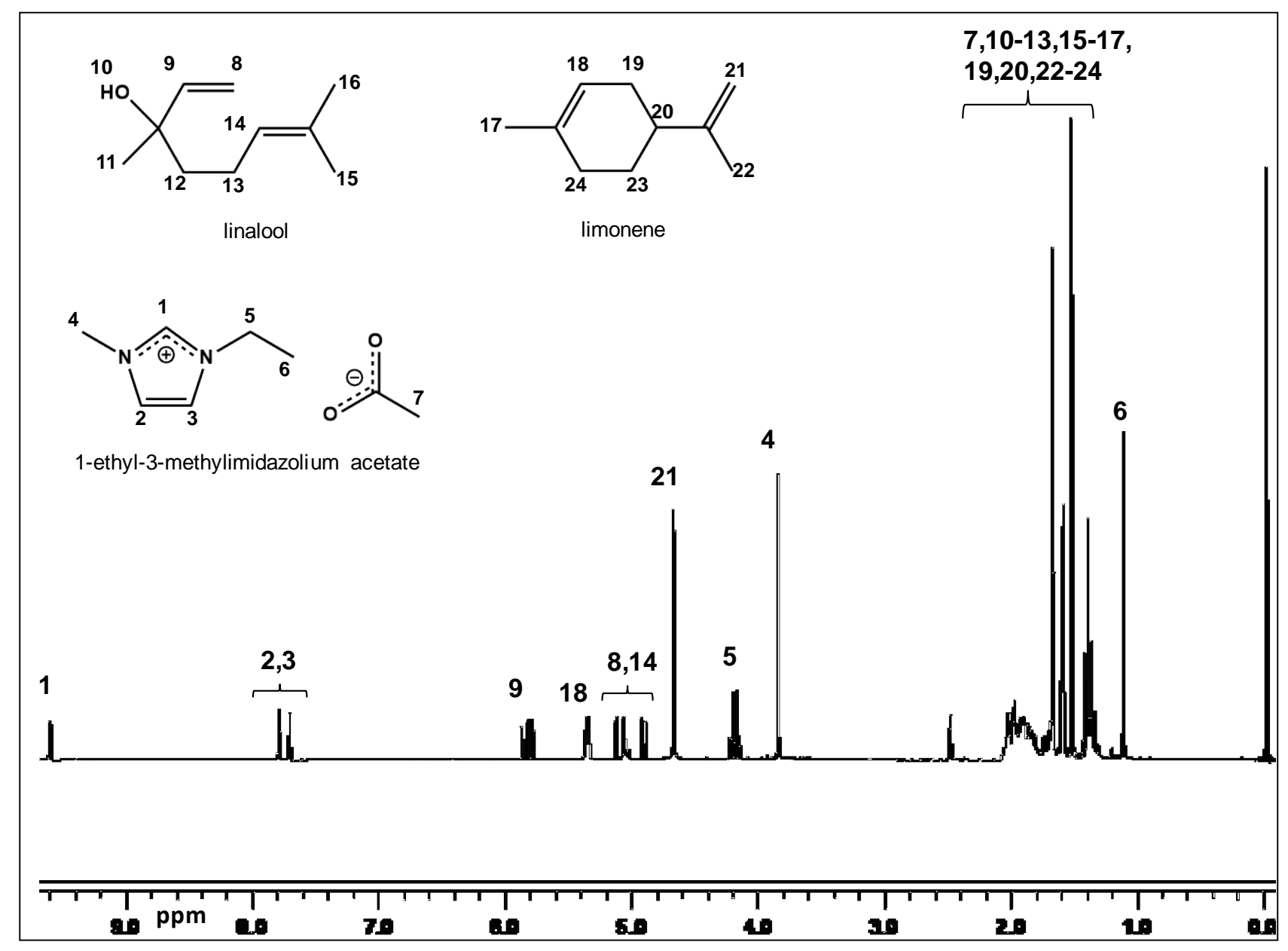

Fig. 2. Example of ${ }^{1} \mathrm{H}$ NMR spectrum for a ternary mixture of limonene, linalool and $\left[\mathrm{C}_{2} \mathrm{mim}\right][\mathrm{OAc}]$, showing the assignment of peaks to hydrogen atoms in the chemical structures of the compounds. 


\section{Figure 3}
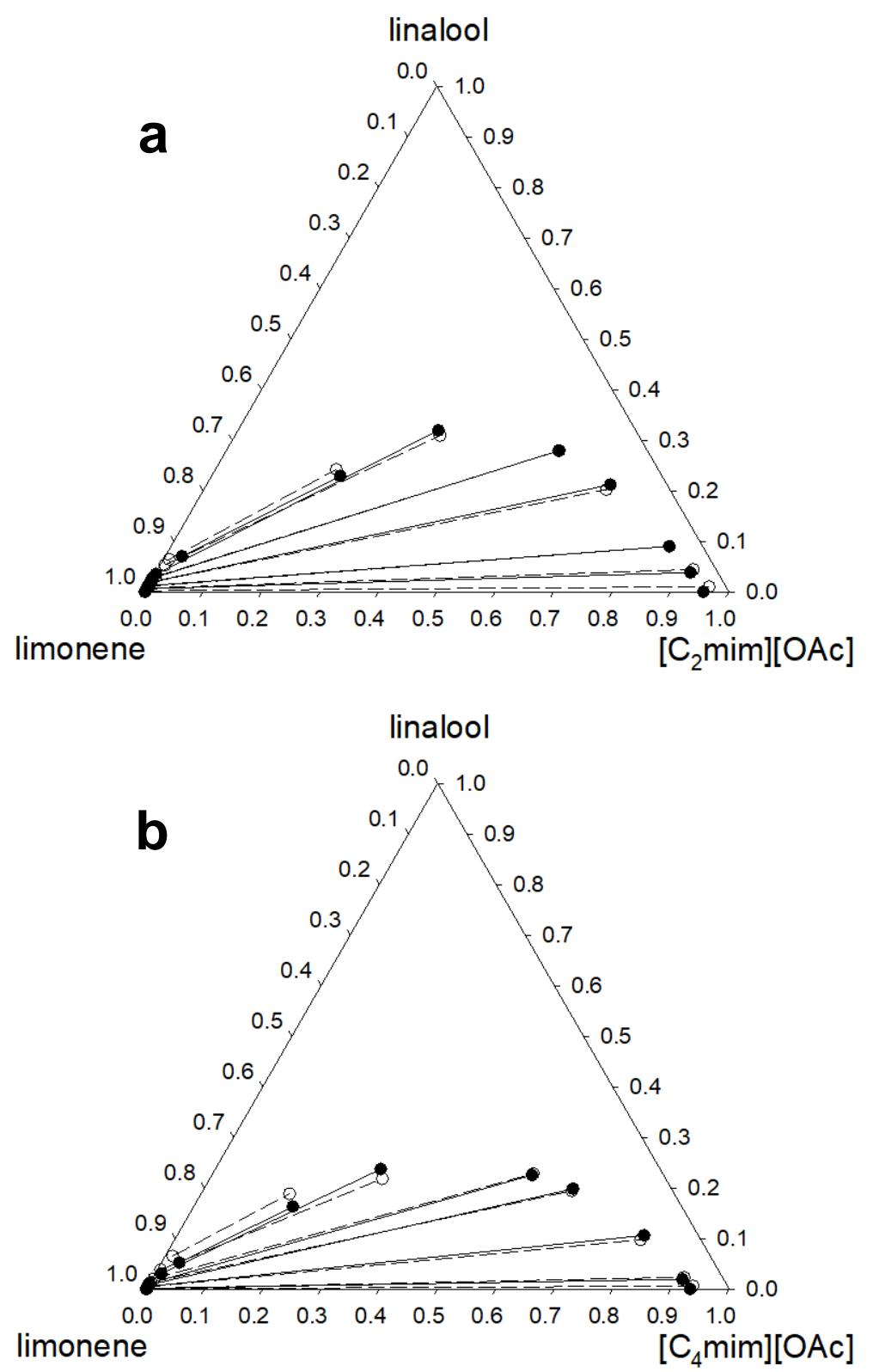

Fig. 3. Experimental tie-lines (solid circles, solid lines), and their corresponding correlated tie-lines obtained with the NRTL model ( $\alpha=0.3$ ) with a previously fixed value of $\beta_{\infty}$ (open circles, dashed lines), for the ternary systems limonene + linalool + ionic liquid, at 298.15 K

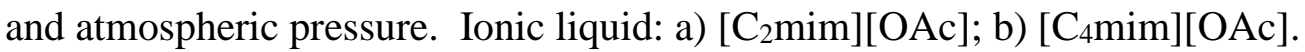




\section{Figure 4}
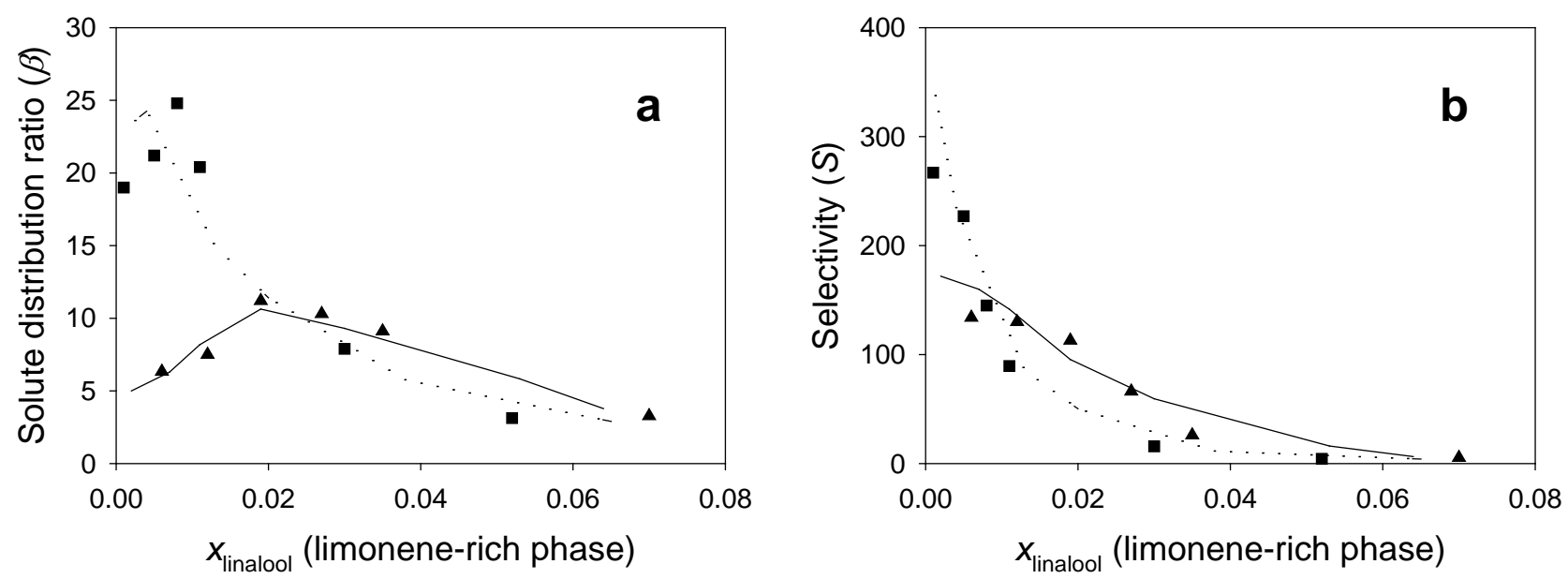

Fig. 4. Experimental values of a) the solute distribution ratio $(\beta)$ and $b)$ the selectivity $(S)$, as a function of the molar fraction of linalool in the limonene-rich phase ( $\left.x_{\text {linalool }}\right)$, for the systems limonene + linalool $+\left[\mathrm{C}_{2} \mathrm{mim}\right][\mathrm{OAc}]$ (triangles) and limonene + linalool + [C4mim][OAc] (squares), at $298.15 \mathrm{~K}$ and atmospheric pressure. The correlated values obtained with the NRTL model ( $\alpha=0.3$ ) fixing $\beta_{\infty}$ are plotted as solid lines for the system with $\left[\mathrm{C}_{2} \mathrm{mim}\right][\mathrm{OAc}]$ and as dashed lines for the system with [ $\left.\mathrm{C}_{4} \mathrm{mim}\right][\mathrm{OAc}]$. 


\section{Figure 5}
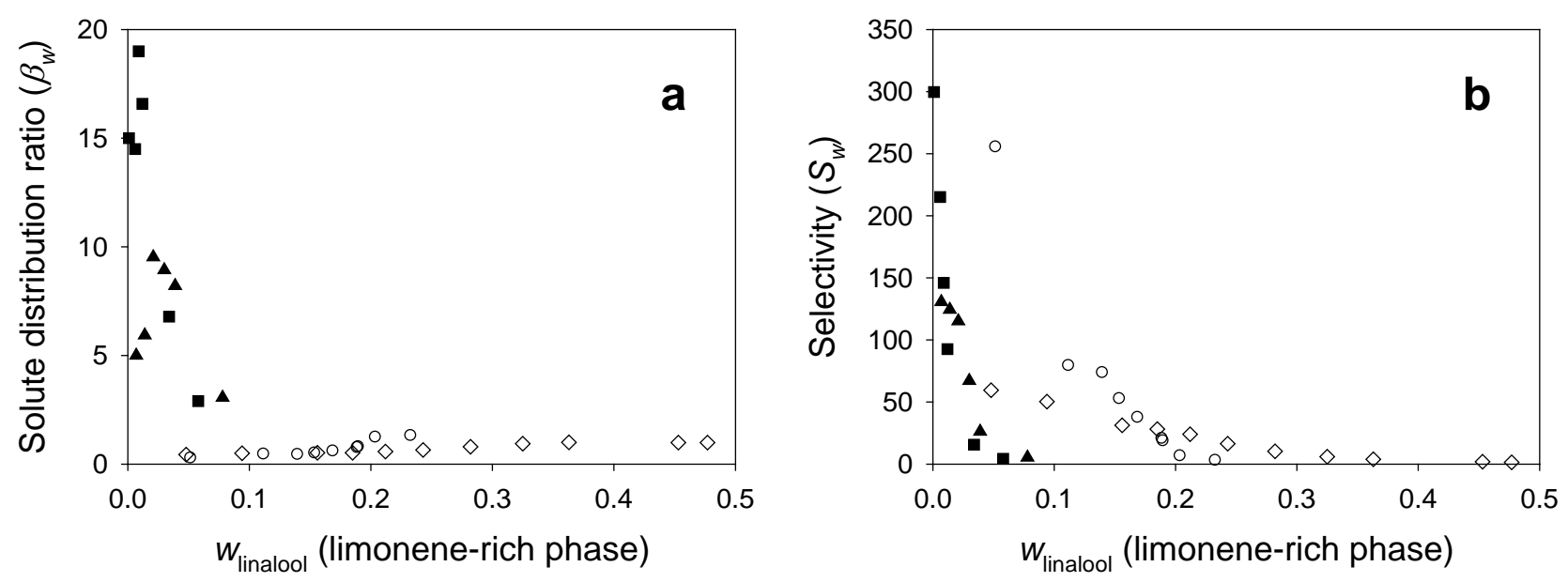

Fig. 5. Experimental values of a) the solute distribution ratio $\left(\beta_{w}\right)$ and b) the selectivity $\left(S_{w}\right)$, in a mass fraction basis, as a function of the mass fraction of linalool in the limonene-rich

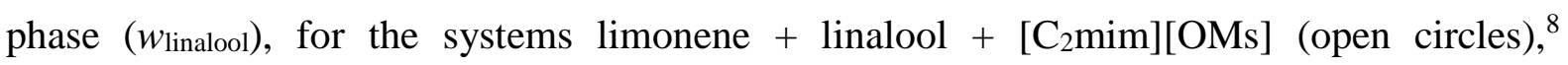
limonene + linalool $+\left[\mathrm{C}_{2} \mathrm{mim}\right]\left[\mathrm{EtSO}_{4}\right]$ (open diamonds), ${ }^{16}$ limonene + linalool + $\left[\mathrm{C}_{2} \mathrm{mim}\right][\mathrm{OAc}]$ (solid triangles), and limonene + linalool $+\left[\mathrm{C}_{4} \mathrm{mim}\right][\mathrm{OAc}]$ (solid squares), at 298.15 K and atmospheric pressure. 


\section{Figure 6}
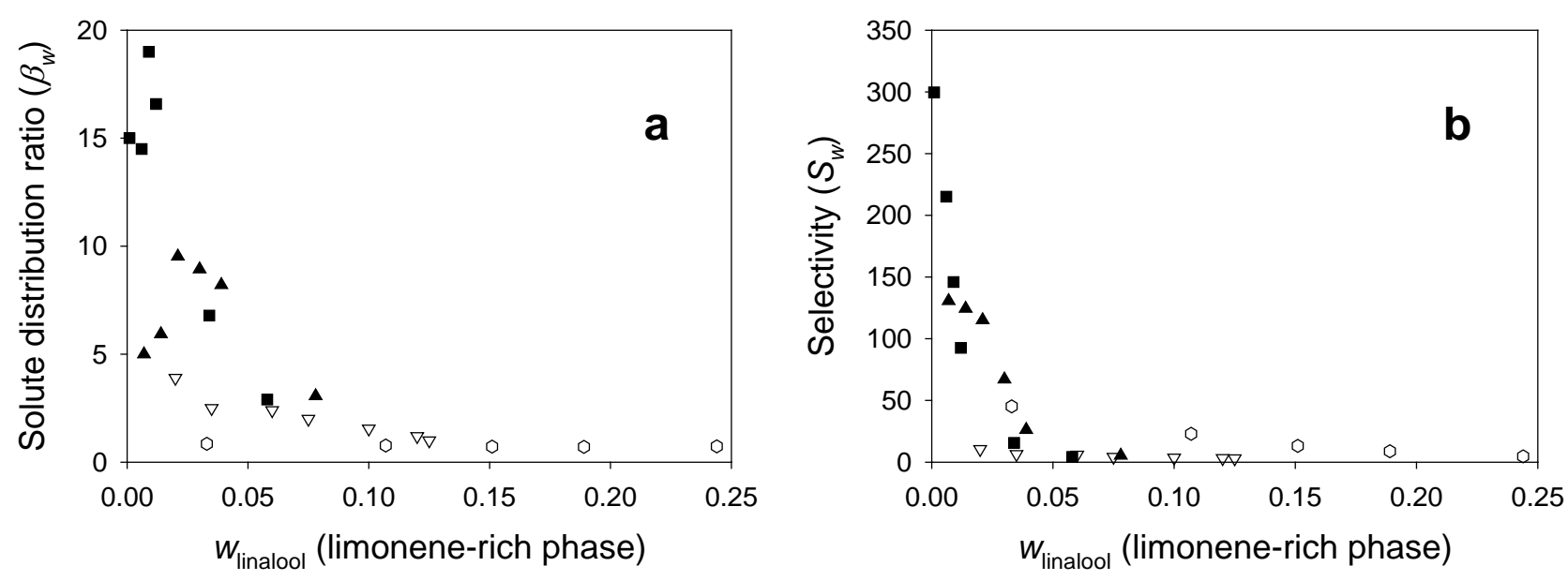

Fig. 6. Experimental values of a) the solute distribution ratio $\left(\beta_{w}\right)$ and b) the selectivity $\left(S_{w}\right)$, in a mass fraction basis, as a function of the mass fraction of linalool in the limonene-rich phase ( $\left.w_{\text {linalool}}\right)$, for the systems limonene + linalool + diethylene glycol (open hexagons), ${ }^{36}$ limonene + linalool $+\left(15: 85 \mathrm{wt} / \mathrm{wt}\right.$ mixture of water + ethanol) (inverted triangles), ${ }^{37}$ limonene + linalool $+\left[\mathrm{C}_{2} \mathrm{mim}\right][\mathrm{OAc}]$ (solid triangles) and limonene + linalool + [C4mim][OAc] (solid squares), at $298.15 \mathrm{~K}$ and atmospheric pressure. 